УДК 664

\title{
ИССЛЕДОВАНИЕ ПРОЦЕССА ПРЕДВАРИТЕЛЬНОЙ ТЕПЛОВОЙ ОБРАБОТКИИ ПОЛУФАБРИКАТА В ИК-БЛАНШИРОВАТЕЛЕ НЕПРЕРЫВНОГО ДЕЙСТВИЯ В ТЕХНОЛОГИИ ФАРШЕВЫХ РЫБНЫХ КОНСЕРВОВ, ОБОГАЩЕННЫХ ЦЕННЫМИ ПИЩЕВЫМИ КОМПОНЕНТАМИ
}

\section{Шушкова Ольга Александровна} магистрант Мандрыка Константин Станиславович аспирант Шокин Григорий Олегович аспирант Научный руководитель: Шокина Юлия Валерьевна д.т.н., профессор ФГАОУ ВО «Мурманский государственный технический университет»

Аннотация: предложена технология фаршевых рыбных поликомпонентных консервов, обогащенных хондроитинсульфатом ската звездчатого. Экспериментально обоснован режим предварительной тепловой обработки полуфабриката - крыльев ската звездчатого дефростированных и обесшкуренных, имеющей целью термическое разложение мочевины и снижение еe массовой доли до значений, гарантирующих высокие органолептические свойства готовой продукции. Экспериментально определены теплофизические характеристики полуфабриката и исследована кинетика его нагрева в процессе ИК-бланширования в установке непрерывного действия, рассчитаны температурные градиенты. По результатам исследований рекомендованы оптимальные режимы ПТО полуфабриката.

Ключевые слова: ИК-бланширование, обогащенные продукты, рыбные консервы, фаршевые продукты 


\title{
RESEARCH OF THE PROCESS OF PRELIMINARY HEAT TREATMENT OF A SEMI-FINISHED PRODUCT IN A CONTINUOUS IR-BLANCHER IN THE TECHNOLOGY OF MINCED CANNED FISH ENRICHED WITH VALUABLE FOOD COMPONENTS
}

\author{
Shushkova Olga Alexandrovna \\ Mandryka Konstantin Stanislavovich \\ Shokin Grygoriy Olegovich \\ Scientific adviser: Shokina Yulia Valerievna
}

\begin{abstract}
: the technology of minced fish multicomponent canned food enriched with chondroitin sulfate of thorny skate is proposed. The mode of preliminary heat treatment of a semi-finished product (the wings of a thorny skate defrosted and desqueared) with the aim of thermal decomposition of urea and reducing its mass fraction to values that guarantee high organoleptic properties of the finished product, is experimentally justified. The thermophysical characteristics of the semi-finished product are determined experimentally and the kinetics of its heating during IR blanching in a continuous-acting device is studied, temperature gradients are calculated. According to the results of the research, the optimal modes of PHT of the semi-finished product are recommended.
\end{abstract}

Key words: IR-blanching, enriched products, canned fish, minced products

«Стратегия развития пищевой и перерабатывающей промышленности Российской Федерации на период до 2030 года» в качестве приоритетной задачи ставит расширение производства пищевых продуктов с функциональными свойствам и обогащенных незаменимыми компонентами, систематическое употребление которых решает проблему несбалансированного питания и профилактики многих социально значимых заболеваний населения Российской Федерации.

Продукты питания из рыбы и нерыбных объектов промысла традиционно и обоснованно относят к категории продуктов здорового питания, благодаря высокому содержанию в них полноценных по аминокислотному составу 
белков, полиненасыщенных жирных кислот, витаминов, микро- и макроэлементов, а также биологически-активных веществ.

Качественные рыбные консервы пользуются большой популярностью у всех слоёв населения. Добавить их в свой рацион - значит обогатить его перечисленными выше ценными компонентами.

Кроме того, по ряду объективных причин (протяженность страны и удаленность в силу этого большей части территории от сырьевых баз рыбопререработки, сезонность продуктового снабжения в районах Крайнего севера, продовольственное снабжение удаленных воинских гарнизонов и экспедиций и т.п.) рыбные консервы часто выступают единственным источником эссенциальных веществ в питании отдельных групп жителей Российской Федерации. По данным Росстата объемы производства консервированной рыбной продукции неуклонно растут, так среднегодовое производство рыбных консервов за последние пять лет составляет около 600 миллионов условных банок, а среднедушевое потребление рыбных консервов достигло 2 кг в год [1].

В ходе проведенного в период с января 2018 по июнь 2021 года исследования регионального (Мурманская область) потребительского рынка рыбной продукции наблюдается значительное расширение ассортимента фаршевых изделий, в том числе полуконсервов и пресервов, очевидно, обусловленное постоянным совершенствованием технологий производства, модернизацией оборудования для глубокой переработки гидробионтов [2, с. 69-80].

При обосновании выбора базовой технологии изготовления новых рыбных фаршевых консервов были учтены следующие факторы:

- возможность проектировать поликомпонентные рецептуры фаршевых смесей, обеспечивающие заданные свойства и состав готового продукта, на основе фарша из мяса рыб традиционного промысла с добавлением обогащающих добавок натурального происхождения и фарша из новых и нетрадиционных объектов промысла, что особенно актуально в связи с неуклонным ростом их доли в промышленных уловах;

- возможность реализовать более широко комплексный подход к переработке ценного сырья - рыбы и нерыбных объектов промысла - на пищевые цели с вовлечением в переработку отходов от разделки, сырья с механическими повреждениями, малоценных в пищевом отношении рыб, 


\section{ПЕРСПЕКТИВНЫЕ РАЗРАБОТКИ ПО ПРИОРИТЕТНЫМ НАПРАВЛЕНИЯМ РАЗВИТИЯ}

нетрадиционных и новых объектов промысла, чаще всего направляемого на утилизацию или кормовое и техническое использование;

- широкие возможности для создания продуктовых линеек аналогичных продуктов, различающихся органолептическими свойствами, но при этом с одинаково высокой пищевой ценностью, что актуально для сохранения производителями продукции доли рынка в условиях жесткой конкуренции;

- высокий экономический эффект от внедрения подобных технологий, формирующийся за счет всех перечисленных выше особенностей.

В Баренцевом море основу прилова при промысле трески составляют скаты, среди которых лидирует по объемам скат звездчатый, который относится к хрящевым рыбам. Переработка ската на пищевые цели активно ведется в странах Юго-Восточной Азии и в некоторых европейских странах, в частности, в Испании и Португалии. При этом для российской рыбопереработки скат остается все еще достаточно экзотическим объектом.

Основной проблемой в этом случае видится отсутствие технологий пищевого использования этой ценной в пищевом отношении рыбы, характеризующейся высоким содержанием белка полноценного по аминокислотному составу, богатым минеральным составом и высоким содержанием физиологически функционального пищевого соединения хондроитинсульфата, который обладает клинически подтвержденным противовоспалительным и хондропротекторным действием [3, с. 451-459; 4, с. 32-39].

В Мурманском государственном техническом университете разработана технология изготовления фаршевых консервов, которая предусматривает предварительную тепловую обработку (ПТО) полуфабриката - крыльев ската путем кратковременного ИК-бланширования в установке периодического действия. Цель ПТО - удаление части влаги из полуфабриката, а также снижение массовой доли мочевины в мясе рыбы вследствие ступенчатого термического разложения этого соединения при температуре выше $60{ }^{\circ} \mathrm{C}$ [5, с. 104-107]. Мочевина ухудшает органолептические свойства продуктов из ската звездчатого при массовой доли 1 \% и выше [6, с. 44-50 ]. Подобранные технологические режимы терморадиационной обработки полуфабриката обеспечивают нагрев поверхности рыбы до $75^{\circ} \mathrm{C}$, а в центре крыла - до $56^{\circ} \mathrm{C}$, что обеспечивает экспериментально подтвержденную эффективность снижения массовой доли мочевины на уровне около 50 \% [7, с. 836-844]. 
К недостаткам разработанной технологии следует отнести периодический характер работы ИК-бланширователя, что снижает производительность технологической линии по выпуску консервов. Переход к непрерывному процессу ПТО позволит решить данную проблему, а включение в состав рецептуры новых видов сырья будет способствовать расширению ассортимента продукции с учетом потребительских предпочтений, выявленных на стадии маркетингового исследования.

С учетом вышеизложенного целью проводимых исследований являлось создание технологии обогащенных хондроитинсульфатом ската звездчатого фаршевых рыбных консервов с ПТО в ИК-бланширователе непрерывного действия. Задачи исследования представлены ниже.

1. Разработка технологической схемы изготовления фаршевых консервов, обогащенных хондроитинсульфатом ската звездчатого.

2. Определение теплофизических характеристик (ТФХ) крыльев ската звездчатого дефростированных и обесшкуренных - полуфабриката для изготовления фаршевых консервов - методом с элементами импульсного теплового контроля, подробно описанном в [8].

3. Изучение кинетики нагрева крыльев ската звездчатого в процессе ИКбланширования в установке непрерывного действия в зависимости от влияющих факторов.

4. Расчет градиентов температуры в толще крыла ската при ИКблншировании и анализ интенсивности его нагрева.

5. Разработка рекомендаций по предварительной тепловой обработке крыльев ската путем ИК-бланширования в установке непрерывного действия для снижения массовой доли мочевины путем ее термического разложения.

На рис. 1 представлена разработанная технологическая схема производства рыбных фаршевых консервов, обогащенных хондроитинсульфатом ската звездчатого.

Результаты эксперимента по определению ТФХ крыла ската звездчатого с массовой долей влаги $82 \%$ приведены ниже. В ходе экспериментов установлены значения параметров - коэффициента теплопроводности $\lambda(\mathrm{BT} /(\mathrm{M} \cdot \mathrm{K}), \quad$ коэффициента потенциалопроводности теплопереноса (коэффициента температуропроводности) а $\left(\mathrm{M}^{2} / \mathrm{c}\right)$ и объемной теплоемкеости $(C \cdot \rho)$, кДж/( $\left.\mathrm{M}^{3} \cdot \mathrm{K}\right)$. 


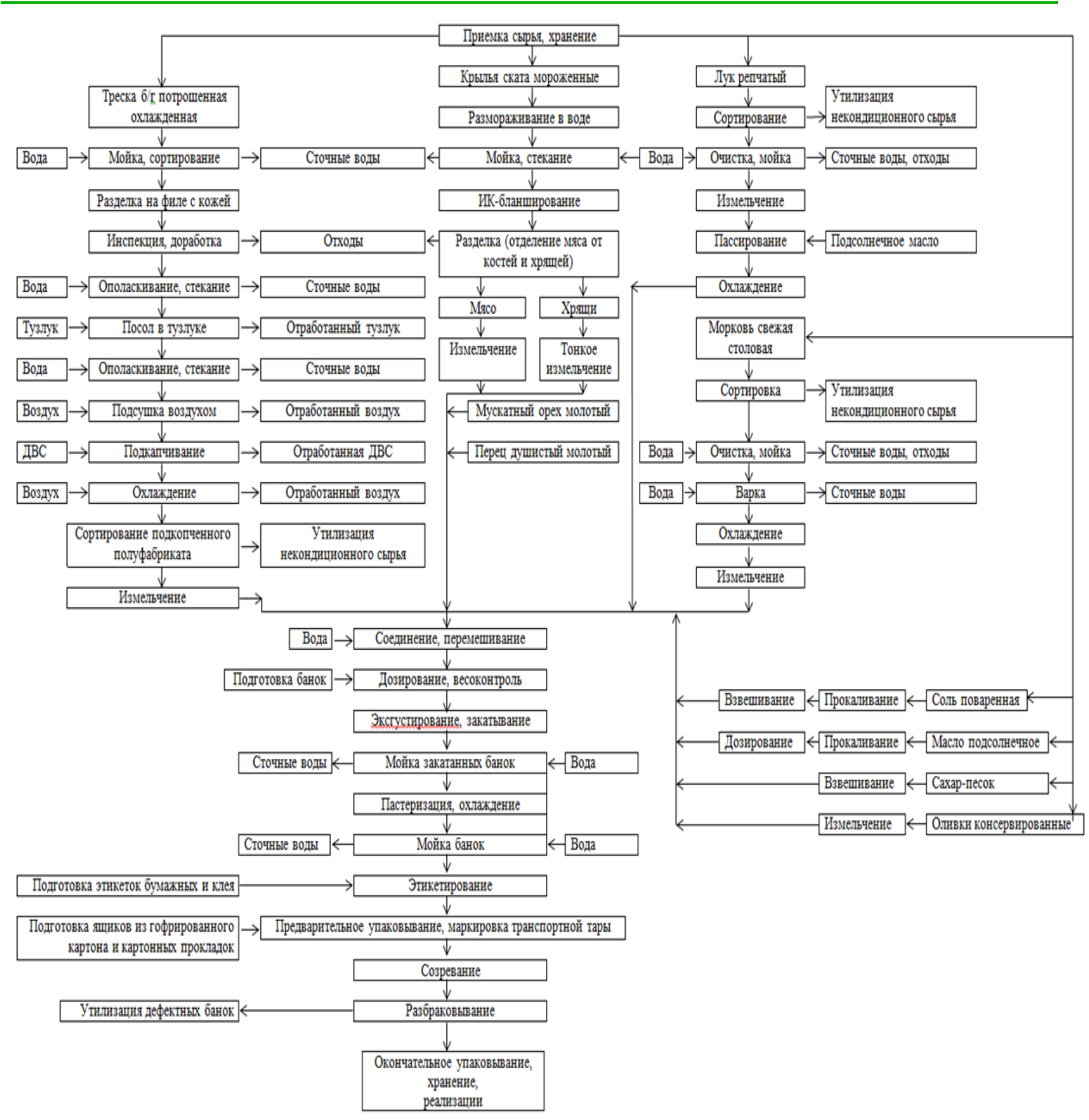

\section{Рис. 1. Технологическая схема изготовления фаршевых рыбных поликомпонентных консервов «Скат и треска с овощами в горчичном соусе»}

На рис. 2 приведены графические результаты определения избыточной температуры облученной и необлученной поверхностей крыла ската в процессе прохождения теплового ИК-импульса при определении ТФХ указанным выше методом. 


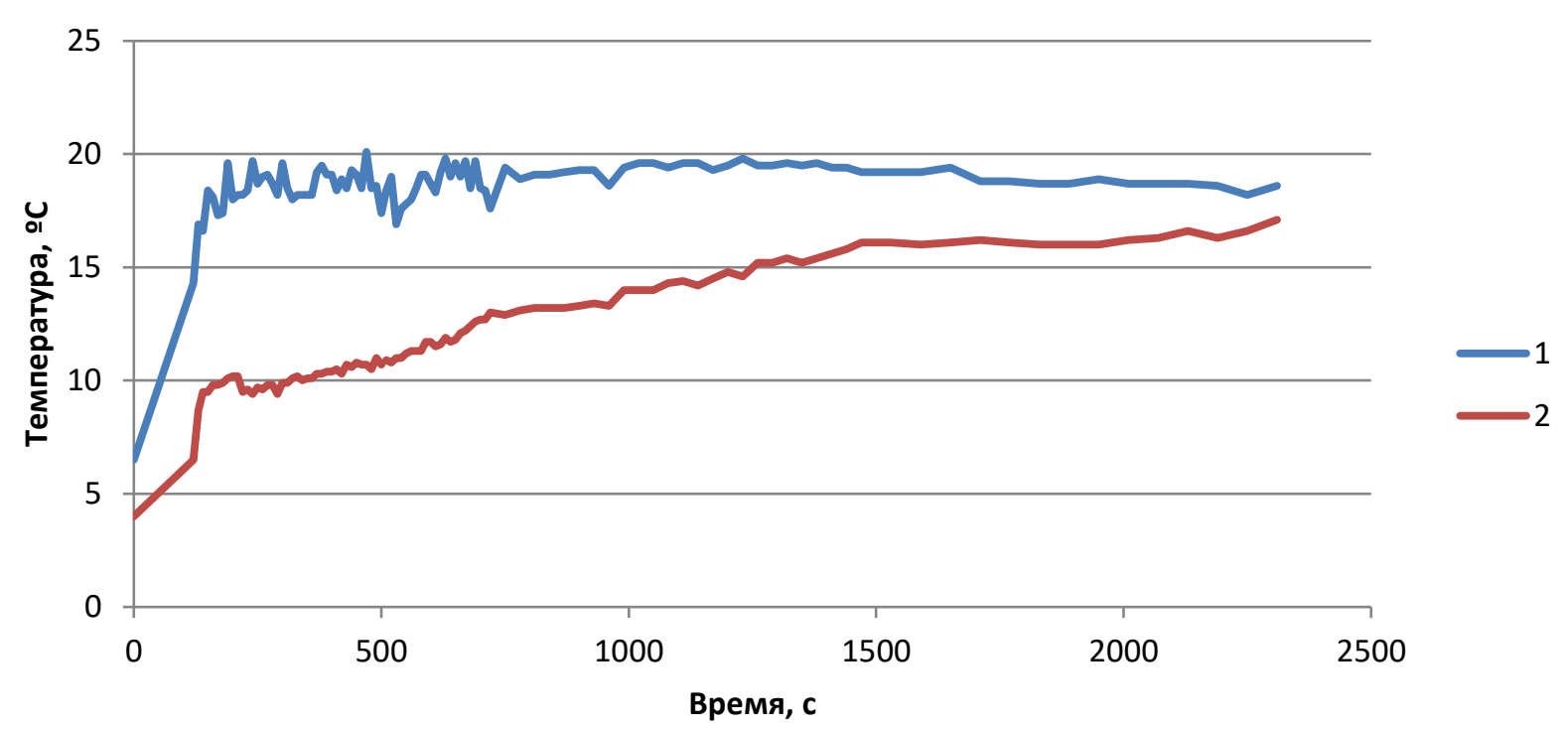

Рис. 2. Кривые кинетики избыточной температуры необлученной и облученной поверхностей крыла ската звездчатого дефростированного и обесшкуренного в процессе прохождения теплового ИК-импульса:

1 - температура облученной поверхности; 2 - температура необлученной поверхности

В результате расчетов по методу Паркера [9] получены значения ТФХ крыльев ската звездчатого, представленные в таблице 1.

Таблица 1

Теплофизические характеристики крыльев ската звездчатого дефростированных и обесшкуренных, массовая доля влаги $82 \%$ и удельная поверхность $0,23 \pm 0,035 \mathrm{~m}^{2} /$ кг

\begin{tabular}{|c|c|c|c|c|c|c|c|}
\hline \multirow{2}{*}{$\begin{array}{c}\Delta T_{3_{\text {макс }}}, \\
\mathrm{K} \\
\left({ }^{\circ} \mathrm{C}\right)\end{array}$} & \multirow[t]{2}{*}{$\begin{array}{l}L, \\
\mathbf{M}\end{array}$} & \multirow{2}{*}{$\begin{array}{c}\tau_{1 / 2}, \\
\mathrm{C}\end{array}$} & \multicolumn{2}{|c|}{$\begin{array}{r}a, \\
\mathrm{M}^{2} / \mathrm{c} \\
\end{array}$} & \multicolumn{2}{|c|}{$\begin{array}{c}\lambda \cdot 10^{-3}, \\
\mathrm{BT} /(\mathrm{M} \cdot \mathrm{K})\end{array}$} & \multirow{2}{*}{$\begin{array}{c}\text { Объем- } \\
\text { ная } \\
\text { масса } \rho, \\
\text { кг/м } \text { м }^{3}\end{array}$} \\
\hline & & & эксперимент & $\begin{array}{c}\text { Теорети- } \\
\text { ческие } \\
\text { данные }\end{array}$ & эксперимент & $\begin{array}{c}\text { Теорети- } \\
\text { ческие } \\
\text { данные }\end{array}$ & \\
\hline 3,1 & 0,01 & 10 & $1,399 \cdot 10^{-6}$ & $1,46 \cdot 10^{-7}$ & 0,404 & 0,506 & 1050 \\
\hline
\end{tabular}

В таблице 2 представлены данные по определению средней линейной скорости движения ленты конвейера-питателя ИК-бланширователя непрерывного действия (пилотная установка), необходимые для расчета длительности терморадиационного воздействия на полуфабрикат во время ПТО. 


\section{ПЕРСПЕКТИВНЫЕ РАЗРАБОТКИ ПО ПРИОРИТЕТНЫМ НАПРАВЛЕНИЯМ РАЗВИТИЯ}

На ленту конвейера-питателя помещали маркер, изменяя скорость движения ленты, измеряли длительность прохождения маркером заданного расстояния. По полученным данным рассчитывали среднюю линейную скорость движения ленты конвейера-питателя при заданных параметрах.

\section{Таблица 2}

Средняя линейная скорость движения ленты конвейера-питателя ИК-бланширователя непрерывного действия (пилотная установка)

\begin{tabular}{|c|c|c|c|c|c|c|c|}
\hline \multirow{2}{*}{\multicolumn{2}{|c|}{ Параметры }} & \multicolumn{6}{|c|}{ № ח\п } \\
\hline & & 1 & 2 & 3 & 4 & 5 & 6 \\
\hline \multicolumn{2}{|c|}{ Скорость ленты конвейера-питателя, см/с } & 3,45 & 5,4 & 6 & 7,5 & 9,3 & 10,8 \\
\hline \multicolumn{2}{|c|}{ Расстояние, пройденное маркером, м } & 0,2 & 0,75 & 0,2 & 0,2 & 0,2 & 0,2 \\
\hline \multirow{3}{*}{$\begin{array}{c}\text { Длительность прохождения } \\
\text { маркером фиксированного } \\
\text { расстояния }\end{array}$} & ч & 0,077 & 0,1 & 0,02 & 0,017 & 0,012 & 0,009 \\
\hline & мин & 4,5 & 6 & 1,27 & 1 & 0,72 & 0,58 \\
\hline & $\mathrm{c}$ & 277 & 360 & 76 & 60 & 43 & 35 \\
\hline \multirow{3}{*}{$\begin{array}{c}\text { Расчетное значение средней } \\
\text { линейной скорости }\end{array}$} & $\mathrm{M} / \mathrm{\Psi}$ & 2,6 & 7,5 & 10 & 11,76 & 16,67 & 22,2 \\
\hline & $\mathrm{cM} / \mathrm{Mин}$ & 4,3 & 12,5 & 15,7 & 20 & 27,78 & 34,48 \\
\hline & $\mathrm{MM} / \mathrm{c}$ & 0,72 & 2,08 & 2,63 & 3,3 & 4,65 & 5,7 \\
\hline
\end{tabular}

В таблице 3 приведена характеристика условий проведения эксперимента по изучению кинетики нагрева крыльев ската звездчатого в процессе ИКбланширования в установке непрерывного действия.

Таблица 3

Условия проведения эксперимента по изучению кинетики нагрева крыльев ската звездчатого в процессе ИК-бланширования в установке непрерывного действия

\begin{tabular}{|c|c|}
\hline Параметр ${ }^{1}$ & Значение \\
\hline Удельная поверхность, мг $^{2}$ & $0,23 \pm 0,035$ \\
\hline Температура воздуха в цехе, ${ }^{\circ} \mathrm{C}$ & $16 \pm 2$ \\
\hline Относительная влажность воздуха в цехе & $75 \pm 5$ \\
\hline Скорость циркуляции воздуха в цехе, м/с & $0,1 \pm 0,01$ \\
\hline Скорость конвейера, м/ч & 5 \\
\hline Толщина крыла ската, м & $0,02 \pm 0,002$ \\
\hline Расстояние от излучателя до облучаемой поверхности, м & 0,04 \\
\hline $\begin{array}{l}{ }^{1} \text { Все параметры определяли в условиях выхода генератор } \\
\text { стационарный режим, температура излучающей поверхности } \\
\text { мощностью } 1,0 \text { кВт каждый, установлены перпендикулярно наг } \\
\text { полуфабриката с шагом } 0,02 \text { м, всего } 4 \text { штуки). }\end{array}$ & $\begin{array}{l}\text { ИК-излучения на } \\
(300 \pm 5){ }^{\circ} \mathrm{C} \quad(\text { ТЭНы } \\
\text { травлению движения }\end{array}$ \\
\hline
\end{tabular}


На рис. 3 показана кинетика нагрева крыльев ската звездчатого в процессе ИК-бланширования в установке непрерывного действия.

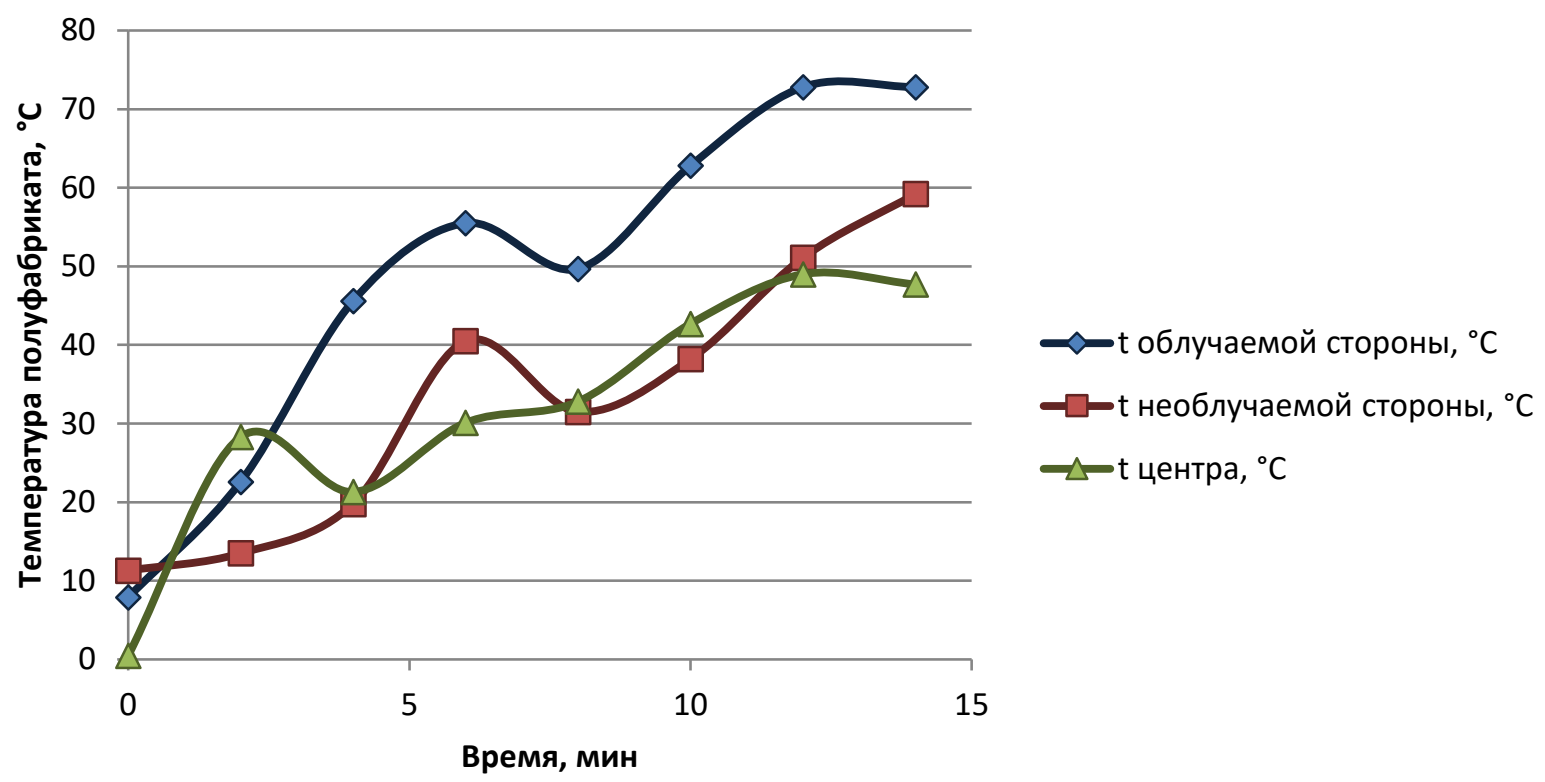

Рис. 3. Кинетика нагрева крыльев ската звездчатого в процессе ИК-бланширования в установке непрерывного действия

Расчетные значения градиентов температуры в крыльях ската в процессе ПТО представлены на рис. 4.

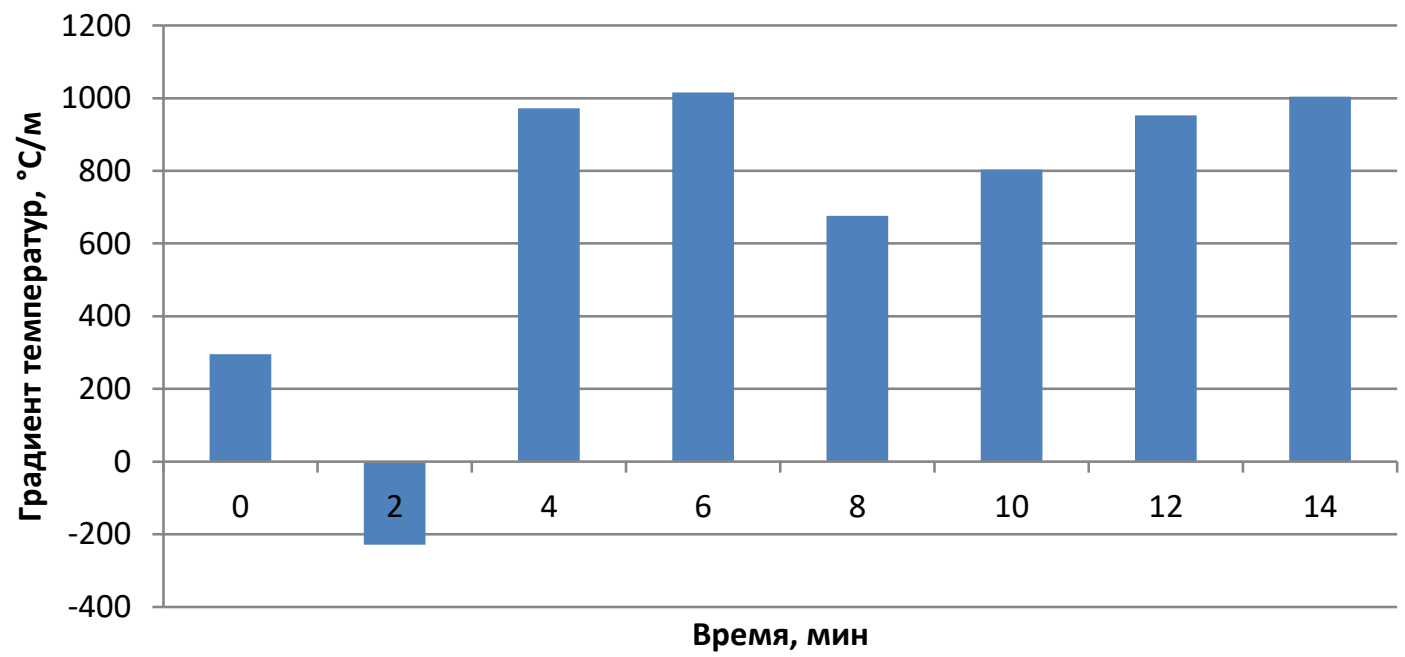

Рис. 4. Расчетные значения градиентов температуры в крыльях ската в процессе ИК-бланширования в установке непрерывного действия 
Сопоставляя данные рис. 3 и 4 с данными таблицы 2, оценив интенсивность нагрева полуфабриката, можем сформулировать вывод о том, что оптимальная скорость движения ленты конвейера-питателя, обеспечивающая максимальную интенсивность нагрева на уровне свыше $1000{ }^{\circ} \mathrm{C} / \mathrm{M}$, является скорость на уровне 27,8 см/мин.

Как видно из рис. 3, температура в геометрическом центре крыла нарастает с отставанием от поверхности. Максимальная температура, достигаемая в процессе ИК-бланширования на поверхности колеблется около $72{ }^{\circ} \mathrm{C}$, а в геометрическом центре крыла за то же время достигается температура от 48 до $50{ }^{\circ} \mathrm{C}$, при этом температура необлучаемой поверхности колеблется от 50 до $60{ }^{\circ} \mathrm{C}$.

По результатам проведенных исследований на пилотной установке ИКбланширователя непрерывного действия при скорости движения ленты 27,8 см/мин или 4,65 мм/с крыло ската нагревается до температуры, при которой начинается ступенчатый распад мочевины за 12 минут, при этом на поверхности рыбного полуфабриката отсутствуют тепловые ожоги. Такой режим можно рекомендовать в качестве основного для ПТО крыльев ската звездчатого с целью снижения массовой доли мочевины.

По результатам проведенных исследований сформулированы следующие выводы:

- разработана технологическая схема изготовления фаршевых консервов, обогащенных хондроитинсульфатом ската звездчатого;

- определены ТФХ полуфабриката для изготовления фаршевых консервов - крыльев ската звездчатого дефростированных и обесшкуренных методом с элементами импульсного теплового контроля;

- изучена кинетика нагрева крыльев ската звездчатого в процессе ИКбланширования в установке непрерывного действия в зависимости от выбранных влияющих факторов;

- рассчитаны градиенты температуры в толще крыла ската, возникающие в процессе ПТО и проанализирована интенсивность нагрева полуффабриката;

- разработаны рекомендации по ПТО крыльев ската ИКбланшированием в установке непрерывного действия для снижения массовой доли мочевины путем ее ступенчатого термического разложения. 


\section{Список литературы}

1. Анализ рынка рыбных консервов в россии в 2015-2019 гг., оценка влияния коронавируса и прогноз на 2020-2024 гг. : сайт.- URL : https://businesstat.ru/images/demo/canned_fish_russia_demo_businesstat.pdf (дата обращения: 17.09.2021).

2. Шушкова О.А. Исследование регионального рынка рыбной кулинарной пастообразной продукции в целях обоснования разработки инновационных технологий и расширения ассортимента // Известия высших учебных заведений. Арктический регион. - 2018. - № 1. - С. 69-80.

3. Krichen, F., Bougatef H., et al. Isolation, Purification and Structural Characterestics of Chondroitin Sulfate from Smooth hound Cartilage: In vitro Anticoagulant and Antiproliferative Properties // Carbohydrate Polymers. - 2018. vol. 197. - pp. 451-459.

4. Krichen, F., Volpi, N. et al. Purification, structural characterization and cantiproliferative properties of chondroitin sulfate/dermatan sulfate from Tunisian fish skins // International Journal of Biological Macromolecules. - 2017. - vol. 95. pp. 32-39.

5. Райбулов С.П., Шокина Ю.В. Пищевая и биологическая ценность функциональных фаршевых консервов из ската звездчатого (Amblyraja radiate) // Рыбное хозяйство. - 2021. - № 2. - С. 104-108.

6. Скачков, В.П. Пищевое использование мяса океанических хрящевых рыб / В.П. Скачков. - М. : Пищ. пром-сть, 1975. - 56 с.

7. Raybulov Sergey Technology of Minced Fish Canned Food from Thorny Skate, Enriched with ChondroitinSulfate // International applied research conference «Biological Resources Development and Environmental Management»,KnELife Sciences, pp. 819-835.

8. Власов А.Б., Шокин Г.О., Шокина Ю.В. Способ определения параметров теплофизических характеристик слоя сыпучих технологических материалов. - Пат. 2616343 Российская Федерация, МПК 25/18 (2006.01), 33/02 (2006.01), 33/46 (2006.01) / А.Б. Власов, Ю.В. Шокина, Г.О. Шокин; заявитель и патентообладатель МГТУ. - заявл. № 20151151929, 03.12.2015; опубл. 14.04.2017, Бюлл. № 11.

9. Parker, W.J. A Flash Method of Determining Thermal Diffusivity, Heat Capasity, and Thermal Conductivity // U.S. Navy Report USNRDL-TR-424, May 1960. 